\title{
A Self-management Approach for Dietary Sodium Restriction in Patients With CKD: A Randomized Controlled Trial
}

\author{
Jelmer K. Humalda, Gerald Klaassen, Hanne de Vries, Yvette Meuleman, Lara C. Verschuur, \\ Elisabeth J.M. Straathof, Gozewijn D. Laverman, Willem Jan W. Bos, Paul J.M. van der Boog, Karin M. Vermeulen, \\ Olivier A. Blanson Henkemans, Wilma Otten, Martin H. de Borst, Sandra van Dijk, and Gerjan J. Navis, on behalf \\ of the SUBLIME Investigators
}

Rationale \& Objective: Patients with chronic kidney disease (CKD) are particularly sensitive to dietary sodium. We evaluated a self-management approach for dietary sodium restriction in patients with CKD.

Study Design: Randomized controlled trial.

Setting \& Participants: Nephrology outpatient clinics in 4 Dutch hospitals. 99 adults with CKD stages 1 to 4 or a functioning (estimated glomerular filtration rate $\geq 25 \mathrm{~mL} / \mathrm{min} / 1.73 \mathrm{~m}^{2}$ ) kidney transplant, hypertension, and sodium intake $>130 \mathrm{mmol} / \mathrm{d}$.

Intervention: Routine care was compared with routine care plus a web-based self-management intervention including individual e-coaching and group meetings implemented over a 3-month intervention period, followed by e-coaching over a 6-month maintenance period.

Outcomes: Primary outcomes were sodium excretion after the 3-month intervention and after the 6-month maintenance period. Secondary outcomes were blood pressure, proteinuria, costs, quality of life, self-management skills, and barriers and facilitators for implementation.

Results: Baseline estimated glomerular filtration rate was $55.0 \pm 22.0 \mathrm{~mL} / \mathrm{min} / 1.73 \mathrm{~m}^{2}$. During the intervention period, sodium excretion decreased in the intervention group from $188 \pm 8$ (SE) to $148 \pm 8 \mathrm{mmol} / \mathrm{d} \quad(P<0.001)$, but did not change significantly in the control group. At 3 months, mean sodium excretion was
$24.8(95 \% \mathrm{Cl}, 0.1-49.6) \mathrm{mmol} / \mathrm{d}$ lower in the intervention group $(P=0.049)$. At 3 months, systolic blood pressure (SBP) decreased in the intervention group from $140 \pm 3$ to $132 \pm 3 \mathrm{~mm}$ $\mathrm{Hg}(P<0.001)$, but was unchanged in the control group. Mean difference in SBP across groups was $-4.7(95 \% \mathrm{Cl},-10.7$ to 1.3$) \mathrm{mm} \mathrm{Hg}$ $(P=0.1)$. During the maintenance phase, sodium excretion increased in the intervention group, but remained lower than at baseline at $160 \pm 8 \mathrm{mmol} / \mathrm{d}(P=0.01)$, while it decreased in the control group from $174 \pm 9$ at the end of the intervention period to $154 \pm 9 \mathrm{mmol} /$ $\mathrm{d}(P=0.001)$. Consequently, no difference in sodium excretion between groups was observed after the maintenance phase. There was no difference in SBP between groups after the maintenance phase.

Limitations: Limited power, postrandomization loss to follow-up, Hawthorne effect, lack of dietary data, short-term follow-up.

Conclusions: A coaching intervention reduced sodium intake at 3 months. Efficacy during the maintenance phase was diminished, possibly due to inadvertent adoption of the intervention by the control group.

Funding: Grant funding from the Netherlands Organization for Health Research and Development and the Dutch Kidney Foundation.

Trial registration: Registered at ClinicalTrials.gov with study number NCT02132013.
Complete author and article information (including a list of the SUBLIME

Investigators) provided

before references.

Correspondence to G. Klaassen (g.klaassen@ umcg.nl)

Am J Kidney Dis. 75(6):847-856. Published online January 16, 2020.

doi: 10.1053/

j.ajkd.2019.10.012

(C) 2019 by the National Kidney Foundation, Inc. atients with chronic kidney disease (CKD) are particularly sensitive to excess sodium ${ }^{1}$ and are strongly advised to limit sodium intake. ${ }^{2-4}$ Observational studies revealed the potential of moderately reduced sodium intake, suggesting that every gram less in daily sodium intake is

\section{Editorial, p. 824}

associated with $15 \%$ lower risk for cardiovascular complications and lower risk for kidney failure for both diabetic ${ }^{5}$ and nondiabetic ${ }^{6}$ CKD (15\% and 10\% lower, respectively).

Current approaches to reduce sodium intake are largely unsuccessful: an analysis of more than 10,000 patients with CKD revealed that average sodium intake in patients with CKD was $164 \mathrm{mmol} / \mathrm{d}$, even in the dedicated setting of the nephrology outpatient clinic. ${ }^{7}$ Behavioral approaches may be more fruitful in achieving sodium restriction. ${ }^{8,9}$ Hypertensive patients receiving behavioral counseling in the Trials of Hypertension Prevention (TOHP) I and II had 25\% lower risk for cardiovascular events after 10 to 15 years of follow-up. ${ }^{8}$ Likewise, the Effects of Self-monitoring on Outcome of Chronic Kidney Disease (ESMO) Study, which was based on self-regulation theory, successfully reduced sodium excretion and blood pressure (BP) in patients with CKD. ${ }^{9}$

Several studies showed that self-regulation theory-based interventions are associated with good outcomes. ${ }^{10-14}$ A qualitative study in CKD on barriers and 
facilitators for sodium restriction yielded several recommendations for future intervention. ${ }^{14}$ More recently, a quantitative study in CKD revealed barriers to target for achieving sodium reduction. ${ }^{15}$ Recommendations from these studies were incorporated into the present selfregulation theory-based study.

The 1-to-1 counseling required in behavioral interventions is costly. Use of e-health may improve affordability. To investigate this, we designed the SUBLIME (Sodium Burden Lowered by Lifestyle Intervention: Selfmanagement and E-health Technology) intervention, which included group counseling and a web-based selfmanagement program, and was followed by a maintenance phase. We evaluated the SUBLIME intervention for efficacy and explored costs, barriers, and facilitators for implementation of SUBLIME intervention into clinical practice.

\section{Methods}

\section{Trial Design}

SUBLIME was a randomized controlled trial that compared routine care with routine care plus a web-based selfmanagement dietary sodium reduction intervention delivered through individual e-coaching and group meetings during a 3-month intervention period, followed by e-coaching during a 6 -month maintenance period.

\section{Participants}

Participants were recruited from June 2014 to March 2015 at nephrology outpatient clinics of the 4 participating centers in the Netherlands: Leiden University Medical Center, Leiden; St. Antonius Hospital, Nieuwegein; University Medical Center Groningen, Groningen; and ZGT Hospital, Almelo. Inclusion criteria were age 18 years or older; CKD stages 1 to 4 or kidney transplants recipients, if estimated glomerular filtration rate was $\geq 25 \mathrm{~mL} / \mathrm{min} / 1.73 \mathrm{~m}^{2}$ (no upper limit); urinary sodium excretion at the last 2 visits $>130 \mathrm{mmol} /$ $\mathrm{d}$ or $>150 \mathrm{mmol} / \mathrm{d}$ at the last visit; systolic BP (SBP) $>135 \mathrm{~mm} \mathrm{Hg}$ or diastolic BP (DBP) >85 mm Hg or wellcontrolled BP with antihypertensive therapy; sufficient command of the Dutch language; ability to use the internet; and written informed consent. Exclusion criteria were rapidly and persistently progressive estimated glomerular filtration rate loss, not from acute intermittent origin; $\mathrm{SBP}>170 \mathrm{~mm} \mathrm{Hg}$ or $\mathrm{DBP}>95 \mathrm{~mm} \mathrm{Hg}$ or $\mathrm{SBP}<95 \mathrm{~mm} \mathrm{Hg}$ not responding to withdrawal of antihypertensive medications; history of cardiovascular events less than 6 months ago; kidney transplantation less than 1 year ago; medical conditions likely to interfere with the completion of the study; and previous participation in a similar study.

The medical ethics board approved the study protocol (METc2014/075). The study is registered at ClinicalTrials.gov (NCT02132013) and was performed in accordance to the Declaration of Helsinki.

\section{Intervention}

Participants visited outpatient clinics at baseline and 3 and 9 months for anthropometric and BP measurements, blood sampling, 24-hour urine collection, and assessment of medication use and filled out a questionnaire at each time point. The baseline questionnaire was distributed directly after randomization because the baseline questionnaire was different for the intervention and control groups.

Figure 1 presents a schematic overview of the SUBLIME intervention delivered to participants randomly assigned to the intervention group during the 3-month intervention phase and during the maintenance phase. Coaching was done by dietitians, lifestyle coaches, or research nurses who were trained by certified lifestyle professionals (ie, professionals with a degree in Lifestyle Counseling). The 3-month intervention began with a baseline face-to-face intake, when a home BP monitoring device (Microlife Watch BP Home) was distributed.

The coach also gave participants access and instructions to a web-based self-management program dedicated to sodium restriction. This program consisted of modules addressing self-regulation theory components; exercises to strengthen intrinsic motivation, selfmonitoring with a detailed interactive food diary (designed to visually show the effect of different food choices on sodium intake), self-efficacy (identifying barriers and possible solutions), goal setting, and social support, dealing with relapse, and a summary page delineating a "Plan for Change." Coaches then viewed the Plan for Change and applied motivational interviewing to support patients in attaining goals.

Participants and their partners were invited to attend 2 scheduled 2-hour group coaching sessions (Fig 1) during the 3-month intervention phase. Group size ranged from 3 to 12 participants. During these sessions the coach addressed self-monitoring, skills to decline salty snacks, relapse prevention, and knowledge about "hidden" sodium in processed foods. During the 3-month intervention phase, participants also received individual coaching by telephone or e-mail (e-coaching), with a minimum of 2 individual coaching sessions. During the 6-month maintenance phase, participants were instructed to complete the web-based self-management modules and participants could receive 1 to 4 individual e-coaching sessions (Fig 1).

\section{Outcomes}

The primary outcome of sodium excretion was measured using one 24-hour urine collection. Blood and urinary electrolytes were measured with routine laboratory procedures. Secondary outcomes were BP, costs, proteinuria, health-related quality of life, self-management skills, and evaluation of barriers and facilitators for implementation. Estimated glomerular filtration rate was calculated using the CKD Epidemiology Collaboration (CKD-EPI) equation. ${ }^{16} \mathrm{BP}$ was measured at the outpatient clinic, in upright position, after 5 minutes' rest with an automated oscillometric device (WatchBP Home; Microlife) 3 times with a 1 -minute interval. ${ }^{17}$ The mean of the second and third 


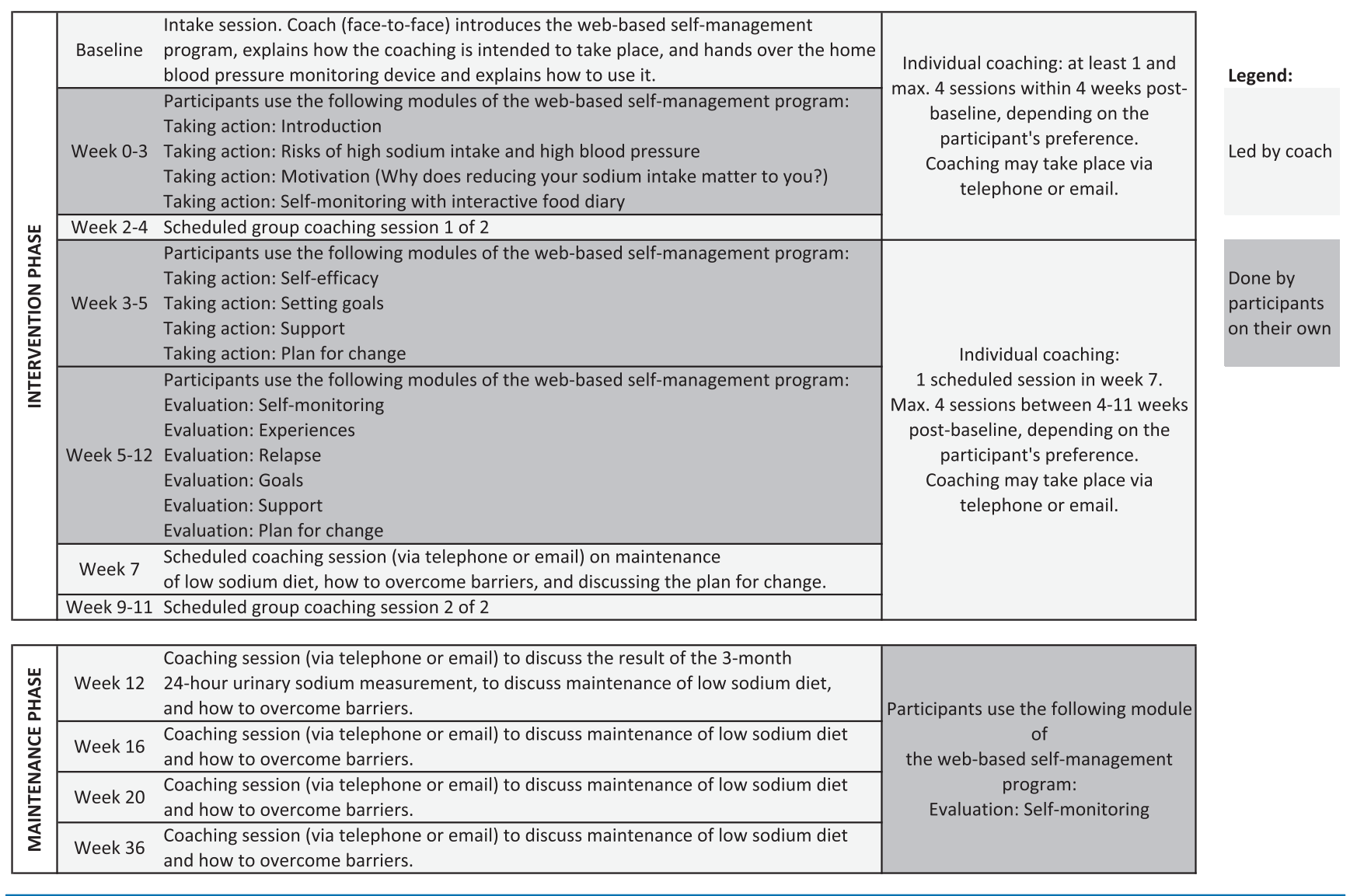

Figure 1. Schematic overview of the SUBLIME (Sodium Burden Lowered by Lifestyle Intervention: Self-management and E-health Technology) intervention.

reading was used for analysis. Proteinuria was measured in a 24-hour urinary collection.

Changes in number of prescribed medications and dosage were explicitly asked at the end of the intervention phase and the maintenance phase and were registered in the Case Report Forms. Questionnaires included sociodemographic factors, 12-Item Short Form Health Survey (SF-12), ${ }^{18}$ EuroQol-5D, ${ }^{19}$ and Partners in Health (PIH) scale. ${ }^{20}$ Health-related quality of life was measured using the SF-12. Scoring ranged from 0 to 100 , with higher scores indicating better quality of life. Self-management skills were assessed using the PIH scale. A 4-item questionnaire was used after the active interventionmaintenance phase, assessing patients' health care consumption. Additionally, data for medication use (type and dosage) and time receiving e-coaching were gathered. These health care consumption data were used for explorative calculation of health care costs, to explore the affordability of the intervention. ${ }^{21}$ Case Report Forms were used to ascertain medical and travel expenses. Sick leave from work was assessed using 2 questions in the baseline questionnaire. Relevant cost categories were consultations with the nephrologist, the general practitioner, and the dietician; nursing days; sick leave; and travel expenses.
After completion of the study, we organized focus groups to evaluate the intervention and identify barriers and facilitators for implementation. Focus groups were led by representatives of the Dutch Kidney Patients Association, each session was observed by 2 note takers from a third party. One note taker attended all 4 focus groups (W.O.). Her records of the focus groups served as basis for qualitative analysis and was confirmed by the second observer (O.A.B.H.).

Furthermore, a process evaluation with the providers was conducted using the Measurement Instrument for Determinants of Innovations questionnaire. ${ }^{22}$

\section{Sample Size}

To detect a difference of $2 \mathrm{~g} / \mathrm{d}$ of salt (corresponding to $34 \mathrm{mmol}$ of sodium per day), achieve 2-sided significance of 0.05 and power of $80 \%$, and accounting for $10 \%$ dropout, 42 patients were required in each group. Based on data from previous studies, ${ }^{9,23-25}$ the expected standard deviation was $40 \mathrm{mmol} / \mathrm{d}$.

\section{Randomization}

Randomization was performed by an independent data management organization. The SURVEYSELECT procedure was used for randomization using the software program 
SAS (SAS Institute Inc). Participants were stratified per participating center ensuring equal group size. Until all participants were allocated, randomization was concealed from research staff. Upon receipt of signed informed consent, the local study coordinator allocated a study number and contacted the data management center to receive the randomization result.

\section{Statistical Analysis}

Data are reported as mean \pm standard deviation or standard error (SE) for normally distributed continuous data or median and interquartile range for skewed continuous data. Categorical data are reported as frequency. We performed an intention-to-treat analysis on primary and secondary outcomes using linear mixed-effects model analysis (LMM) with restricted maximum likelihood approach and scaled identity covariance structure for sodium excretion and SBP and DBP at baseline and 3 and 9 months, using all 3 time points in 1 model. Fixed effects were treatment group, time, and time $\times$ treatment group, and random effect was participant number. We report estimated marginal means and SE for continuous outcomes in our LMM. Within-group differences over time of sodium excretion and BP were tested using paired-samples t test.

Within-group differences over time of PIH and SF-12 scores were tested using Wilcoxon signed rank test. Between-groups differences of PIH and SF-12 scores were tested using Mann-Whitney test. Mean change from to baseline of intervention compared to control of $\mathrm{PIH}$ and SF-12 scores was tested using independent samples t test. Occurrence of antihypertensive dose reduction or increase between control and intervention was compared using Fisher exact test.

$\mathrm{P}<0.05$ was considered statistically significant. Analyses were performed with PASW Statistics, version 22.0
(SPSS Inc) and STATA Statistical Software, Release 13 (StataCorp).

\section{Results}

\section{Participant Characteristics}

We randomly assigned 99 patients: 52 intervention and 47 control (Fig 2). Five patients did not attend the baseline measurement visit. Participants were 56.6 \pm 12.4 years old, and $44 \%$ were kidney transplant recipients. Baseline characteristics were similar between the control and intervention groups (Table 1). Five participants were lost to follow-up (Fig 2), and not all participants returned their 24-hour urine collection after baseline.

Data logs revealed that 44 of 50 participants used the program, with most participants using the program the first 2 to 4 months. A total of 1,647 records of daily dietary intake were made (37.4 days per participant) during the study. Participants recorded 4,256 (55.4\%) meals and $3,428 \quad(44.6 \%)$ snacks. Eight participants stopped recording within 1 month, and 11 recorded for longer than 6 months. Within the period that participants recorded, most recorded information every other day.

\section{Outcomes After 3-Month Intervention Phase}

In the intervention group, sodium excretion decreased from $188 \pm 63 \mathrm{mmol} / \mathrm{d}$ at baseline to $148 \pm 55 \mathrm{mmol} / \mathrm{d}$ at 3 months (Fig 3). LMM confirmed that this was a significant reduction, with the estimated marginal mean changing over the 3 months from $188 \pm 8$ (SE) to $148 \pm 8 \mathrm{mmol} / \mathrm{d}$ ( $\mathrm{P}<0.001$ for within-group difference; Table 2). The control group demonstrated a nominal but non-statistically significant reduction in sodium excretion. Compared with control, this reflected an effect of the intervention of $-24.8 \quad(95 \% \quad$ confidence interval

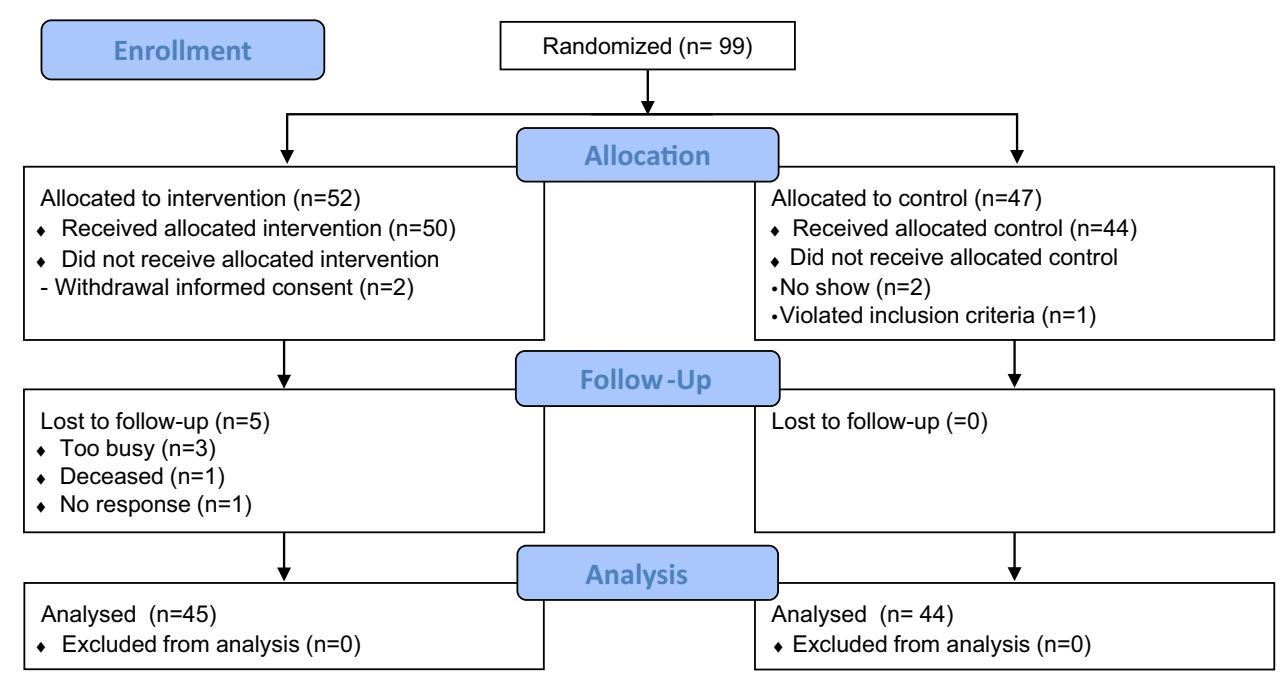

Figure 2. Flow diagram of the SUBLIME (Sodium Burden Lowered by Lifestyle Intervention: Self-management and E-health Technology) intervention. 
Table 1. Baseline Characteristics

\begin{tabular}{|c|c|c|c|}
\hline & $\begin{array}{l}\text { Total } \\
(\mathrm{N}=94)\end{array}$ & $\begin{array}{l}\text { Control } \\
(n=44)\end{array}$ & $\begin{array}{l}\text { Intervention } \\
(n=50)\end{array}$ \\
\hline Age, $y$ & $56.6 \pm 12.4$ & $58.2 \pm 13.2$ & $55.1 \pm 11.5$ \\
\hline Female sex & $15(16 \%)$ & $8(18 \%)$ & $7(14 \%)$ \\
\hline eGFR, mL/min/1.73 $\mathrm{m}^{2}$ & $55.0 \pm 22.0$ & $54.3 \pm 21.6$ & $55.6 \pm 22.6$ \\
\hline \multicolumn{4}{|l|}{ History of DM } \\
\hline None & $65(69 \%)$ & $30(68 \%)$ & $35(70 \%)$ \\
\hline T1DM & $7(7 \%)$ & $3(7 \%)$ & $4(8 \%)$ \\
\hline T2DM & $22(23 \%)$ & $11(25 \%)$ & $11(22 \%)$ \\
\hline History of dialysis & $27(29 \%)$ & $12(27 \%)$ & $15(30 \%)$ \\
\hline $\begin{array}{l}\text { Kidney transplant } \\
\text { recipient }\end{array}$ & $41(44 \%)$ & $19(43 \%)$ & $22(44 \%)$ \\
\hline $\begin{array}{l}\text { Antihypertensive drug } \\
\text { use }\end{array}$ & $90(96 \%)$ & $41(93 \%)$ & $49(98 \%)$ \\
\hline $\begin{array}{l}\text { No. of classes of } \\
\text { antihypertensive drugs }\end{array}$ & $2.0 \pm 1.0$ & $2.0 \pm 1.1$ & $2.1 \pm 1.0$ \\
\hline RAAS blockade & $70(74 \%)$ & $32(73 \%)$ & $38(76 \%)$ \\
\hline$\beta$-Blocker & $41(44 \%)$ & $15(34 \%)$ & $26(52 \%)$ \\
\hline $\begin{array}{l}\text { Calcium channel } \\
\text { antagonist }\end{array}$ & $33(35 \%)$ & $16(36 \%)$ & $17(34 \%)$ \\
\hline Diuretic & $40(43 \%)$ & $22(50 \%)$ & $18(36 \%)$ \\
\hline Calcineurin inhibitor use & $27(29 \%)$ & $12(27 \%)$ & $15(30 \%)$ \\
\hline Possesses HBPM & $64(68 \%)$ & $35(80 \%)$ & $29(58 \%)$ \\
\hline Uses never & $11(17 \%)$ & $6(17 \%)$ & $5(17 \%)$ \\
\hline Uses daily & $5(8 \%)$ & $2(6 \%)$ & $3(10 \%)$ \\
\hline Uses weekly & $19(30 \%)$ & $10(9 \%)$ & $9(31 \%)$ \\
\hline Uses monthly & $29(45 \%)$ & $17(49 \%)$ & $12(41 \%)$ \\
\hline Body mass index, $\mathrm{kg} / \mathrm{m}^{2}$ & $28.6 \pm 5.3$ & $28.4 \pm 5.0$ & $28.7 \pm 5.6$ \\
\hline White & $89(95 \%)$ & $40(91 \%)$ & $49(98 \%)$ \\
\hline Higher educated $^{\mathrm{a}}$ & $39(41 \%)$ & $19(43 \%)$ & $20(40 \%)$ \\
\hline
\end{tabular}

Note: Values given as count (percentage) or mean \pm standard deviation. Abbreviations: DM, diabetes mellitus; eGFR, estimated glomerular filtration rate; HBPM, home blood pressure monitor; RAAS, renin-angiotensin-aldosterone system; T1(2)DM, type 1 (2) diabetes mellitus.

aDefined as "at least finished secondary education to prepare for university."

[CI], -49.6 to -0.1$) \mathrm{mmol} / \mathrm{d}(\mathrm{P}=0.049$ for betweengroup difference; Table 2).

There was a concomitant decrease in SBP (from $140 \pm 16$ to $131 \pm 14 \mathrm{~mm} \mathrm{Hg}$ ) and DBP (from $84 \pm 9$ to $80 \pm 9 \mathrm{~mm} \mathrm{Hg}$ ) in the intervention group (Fig 4). LMM confirmed this, with the estimated marginal mean changing from $140 \pm 3$ to $132 \pm 3 \mathrm{~mm} \mathrm{Hg}(\mathrm{P}<0.001$ for within-group difference; Table 2). In comparison, the change in SBP in the control group (from $139 \pm 3$ to $136 \pm 3 \mathrm{~mm} \mathrm{Hg})$ was not statistically significant $(P=0.2$ for within-group difference). The mean difference in SBP across groups was $-4.7(95 \% \mathrm{CI},-10.7$ to 1.3$) \mathrm{mm} \mathrm{Hg}$ $(\mathrm{P}=0.1)$.

After the intervention phase, 11 participants had proteinuria with protein excretion $\geq 1.0 \mathrm{~g} / \mathrm{d}$ ( 6 intervention and 5 control). Median proteinuria compared with baseline did not markedly change in the intervention group $(P=0.07$ for within-group difference) or the control group $(P=0.2$ for within-group difference).

Antihypertensive drug use in the control group decreased in 1 and increased in 3 participants, whereas it decreased in 5 and increased in 3 participants in the

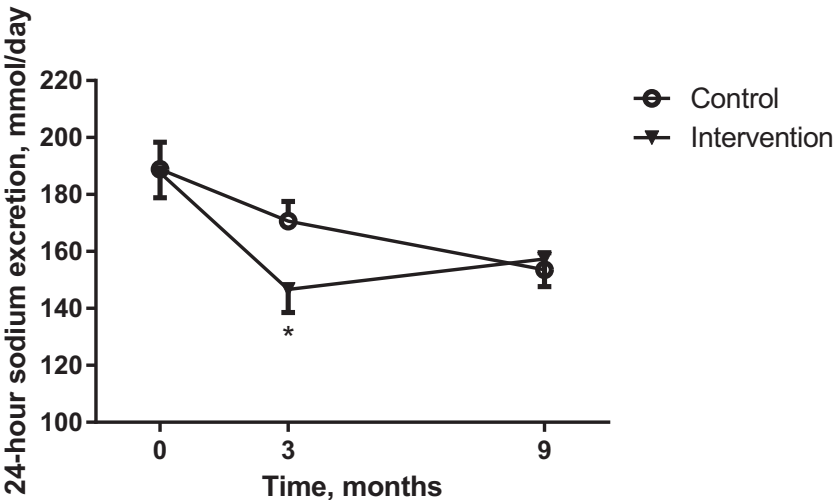

Figure 3. Sodium excretion as assessed by 24-hour urine collection at baseline, after intervention (3 months), and maintenance phase (9 months postbaseline). Within-group change at 9 months compared to baseline (paired-samples $t$ test) was $P=0.01$ for intervention and $P=0.001$ for control. ${ }^{\star} P=0.049$ versus control group. Error bars represent standard error of mean.

intervention group, but these changes were not statistically significant (Fisher exact test, $\mathrm{P}=0.2$ for dose reduction and $P=0.9$ for dose increase).

During the intervention phase, participants in the intervention group received $2.8 \pm 1.2$ sessions of ecoaching. Four participants had 1 e-coaching session and 8 did not request/receive e-coaching (2 due to drop out) according to the coaches' logs.

\section{Outcomes After the 6-Month Maintenance Phase}

The effect on sodium excretion persisted in the intervention group, being $157 \pm 64 \mathrm{mmol} / \mathrm{d}$ after the 6month maintenance phase (Fig 3). LMM confirmed this, with the estimated marginal mean changing from $188 \pm 8 \mathrm{mmol} / \mathrm{d}$ at baseline to $160 \pm 8 \mathrm{mmol} / \mathrm{d}$ at 9 months postbaseline $(\mathrm{P}=0.01$ for within-group difference; Table 2). In the control group, there was a decrease to $154 \pm 40 \mathrm{mmol} / \mathrm{d}$ at 9 months postbaseline (Fig 3). This is reflected in the LMM (Table 2), leading to no significant between-group difference in sodium excretion between the intervention and control groups (Table 2).

A decrease in SBP was observed (from $140 \pm 16$ at baseline to $131 \pm 14 \mathrm{~mm} \mathrm{Hg}$ at 9 months postbaseline) in the intervention group (Fig 4). LMM confirmed this, with the estimated marginal mean changing from $140 \pm 3$ to $132 \pm 3 \mathrm{~mm} \mathrm{Hg}(\mathrm{P}<0.001$ for within-group difference, Table 2). In the control group, there was a nominal decrease in SBP from $139 \pm 3$ to $135 \pm 3 \mathrm{~mm} \mathrm{Hg}(\mathrm{P}=0.1$ for within-group difference). The mean difference in SBP across groups was -4.3 (95\% CI, -10.2 to 1.7$) \mathrm{mm} \mathrm{Hg}$ $(\mathrm{P}=0.2)$.

After the maintenance phase, 11 participants had proteinuria, with protein excretion $\geq 1.0 \mathrm{~g} / \mathrm{d}$ ( 5 intervention and 6 control). Median proteinuria compared with 
Table 2. Linear Mixed-Effects Model of the SUBLIME Intervention

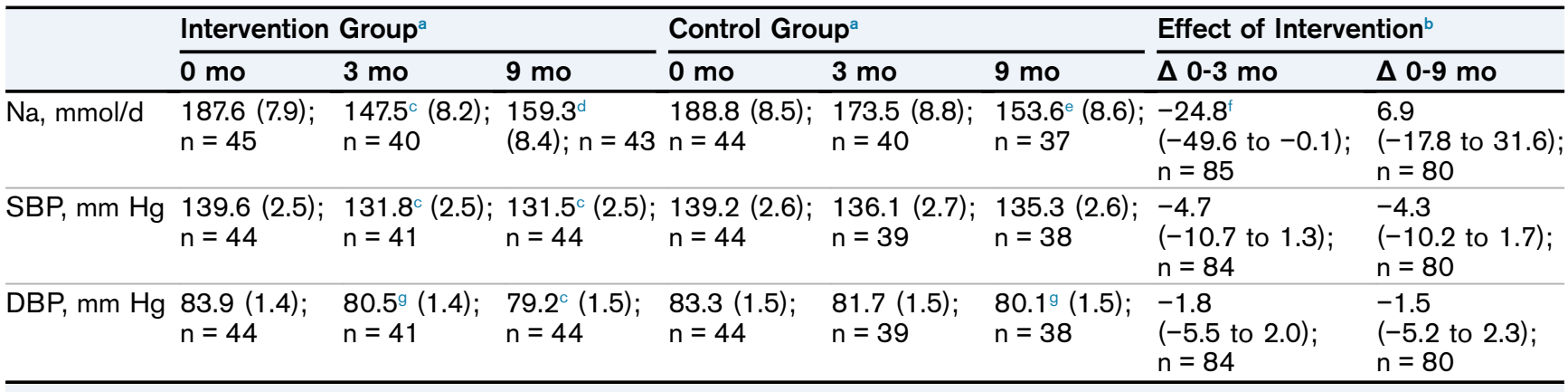

Abbreviations: DBP, diastolic blood pressure; SBP, systolic blood pressure; SUBLIME, Sodium Burden Lowered by Lifestyle Intervention: Self-management and E-health Technology.

${ }^{\mathrm{a}}$ Estimated marginal mean and standard error.

${ }^{b}$ Effect of interaction term time $\times$ treatment with $95 \%$ confidence interval, $n$ refers to number of participants who had both baseline and follow-up outcome measurements available.

${ }^{\mathrm{c}} P<0.001$ versus baseline within group.

${ }^{\mathrm{d}} P=0.01$ versus baseline within group.

${ }^{\text {e }} P=0.001$ versus baseline within group.

${ }^{f} P=0.049$ difference in change versus control group.

${ }^{\mathrm{g}} P=0.03$ versus baseline within group.

baseline did not markedly change after the maintenance phase in the intervention $(P=0.07$ for within-group difference) or control group ( $\mathrm{P}=0.3$ for within-group difference).

Antihypertensive drug use decreased in 5 and increased in 3 participants, in both control and intervention, but these changes were not statistically significant (Fisher exact test, both $P=0.9$ ).

During the maintenance phase, participants in the intervention group received $2.1 \pm 0.6$ sessions of e-coaching; 17 participants did not request or receive e-coaching ( 5 due to drop out) according to the coaches' logs.

\section{Quality of Life and Self-management Skills}

At baseline, the Physical Health Summary score was similar between groups $(\mathrm{P}=0.9$; Table 3$)$. After the intervention

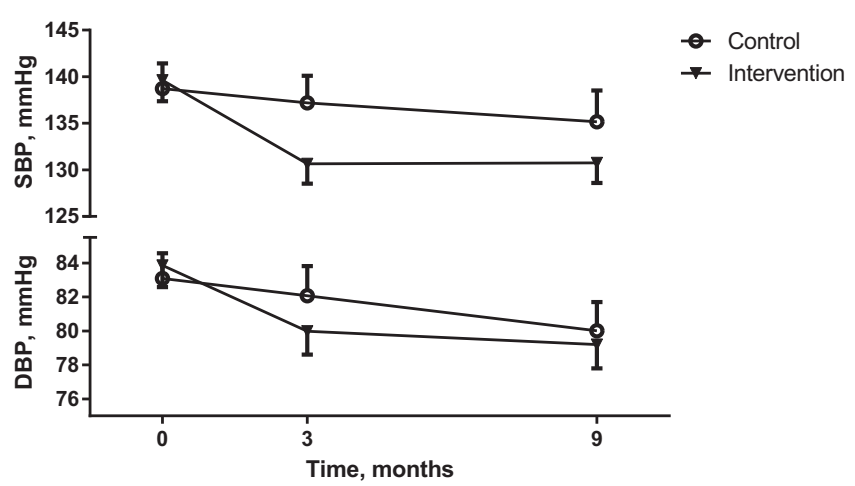

Figure 4. Office blood pressure (BP), after intervention (3 months), and maintenance phase ( 9 months postbaseline). Within-group change in systolic BP (SBP) at 9 months compared to baseline (paired-samples $t$ test) was $P<0.001$ for intervention and $P=0.09$ for control. Within-group change in diastolic BP (DBP) at 9 months compared to baseline (paired-samples $t$ test) was $P<0.001$ for intervention and $P=0.03$ for control. Error bars represent standard error of mean. phase, this score was higher in intervention compared with control $(P=0.04)$; this difference remained after the maintenance phase $(P=0.01)$. At baseline, Mental Health Summary score was similar between groups $(P=0.8)$ and remained so after the intervention phase $(P=0.1)$. After the maintenance phase, the intervention group reported higher Mental Health Summary scores than controls $(\mathrm{P}=0.01)$.

At baseline, PIH scores were similar between groups $(P=0.1$; Table 3). Likewise, after the intervention and maintenance phases, no significant between-group differences in PIH scores were observed $(P=0.6$ and $P=0.5$, respectively).

\section{Costs}

Average total costs per patient for the 9-month intervention were $\$ 506(€ 451)$ in the intervention group and $\$ 460$ (€410) in the control group. This difference in costs is mainly explained by higher costs in dietary care intervention versus control.

\section{Barriers and Facilitators for Implementation: Focus Groups}

Twenty-one intervention participants participated in focus groups. Additionally, 5 partners and 1 daughter took part. Each focus group consisted of 5 to 6 participants per center. Although all intervention components were evaluated, the focus groups primarily discussed the web-based self-management program. Participants deemed the exercises in the program clearly formulated and user friendly, but questioned whether it was necessary to complete exercises that addressed motivation "because we were already motivated, otherwise we would not have participated". The most reported barrier for using the program was filling out the interactive diary because this was time intensive and not all food products were available in the database (or were hard to find). Another barrier was 
Table 3. Self-management Skills and Health-Related Quality of Life

\begin{tabular}{|c|c|c|c|c|c|c|}
\hline & \multicolumn{3}{|c|}{ Intervention Group } & \multicolumn{3}{|c|}{ Control Group } \\
\hline & $0 \mathrm{mo}$ & $3 \mathrm{mo}$ & $9 \mathrm{mo}$ & $0 \mathrm{mo}$ & $3 \mathrm{mo}$ & $9 \mathrm{mo}$ \\
\hline $\mathrm{PIH}$ score & $\begin{array}{l}86[72-102] \\
\mathrm{n}=40\end{array}$ & $\begin{array}{l}93[79-101] \\
\mathrm{n}=36\end{array}$ & $\begin{array}{l}91[76-104] ; \\
\mathrm{n}=35\end{array}$ & $\begin{array}{l}97[82-105] \\
\mathrm{n}=35\end{array}$ & $\begin{array}{l}96[84-104] ; \\
\mathrm{n}=37\end{array}$ & $\begin{array}{l}96[80-106] \\
n=31\end{array}$ \\
\hline SF-12, PHS & $\begin{array}{l}79[59-92] \\
\mathrm{n}=48\end{array}$ & $\begin{array}{l}90^{a}[65-92] \\
\mathrm{n}=44\end{array}$ & $\begin{array}{l}92^{b}[58-92] \\
n=43\end{array}$ & $\begin{array}{l}83[54-92] \\
\mathrm{n}=39\end{array}$ & $\begin{array}{l}54 \text { [33-92]; } \\
\mathrm{n}=37\end{array}$ & $\begin{array}{l}58[38-92] \\
n=40\end{array}$ \\
\hline SF-12, MHS & $\begin{array}{l}83[72-90] \\
n=47\end{array}$ & $\begin{array}{l}83[69-93] \\
n=45\end{array}$ & $\begin{array}{l}86^{b}[75-93] \\
n=42\end{array}$ & $\begin{array}{l}83 \text { [73-93]; } \\
n=40\end{array}$ & $\begin{array}{l}80[47-87] \\
n=38\end{array}$ & $\begin{array}{l}80 \text { [64-87]; } \\
n=40\end{array}$ \\
\hline
\end{tabular}

Note: Data are shown as median [interquartile range], and comparisons were made using Mann-Whitney between groups and Wilcoxon signed rank within groups. Cronbach alpha of PIH, 0.93; Cronbach alpha of SF-12, 0.86 for PHS and 0.84 for MHS.

Abbreviations: MHS, Mental Health Summary; PHS, Physical Health Summary; PIH, Partners in Health; SF-12, 12-ltem Short Form Health Survey.

${ }^{a} P=0.04$ between-groups difference.

${ }^{\mathrm{b}} P=0.01$ between-groups difference.

difficulty estimating sodium content from restaurant meals or combined products. Participants generally valued the "options for change" menu, in which alternative food products could be chosen. Participants expressed that they used the change options to cut sodium intake and plan compensation for excess sodium intake.

When asked to what extent the modules gave insight into actual sodium consumption, participants reported that they highly valued the monitoring module (average, 8.3/ 10). This module gave visual feedback, showing the amount of sodium that participants consumed by consuming certain foods and how this added up compared with their self-determined goal of maximal daily sodium consumption.

Most participants valued the e-coaching and mentioned the importance of personal contact with the coach before the e-coaching. The majority would have appreciated "an unannounced reminder contact" in the maintenance phase to aid their program adherence. The group meetings were valued for providing practical advice and greater awareness and for exchange of experiences and contact with fellow patients. Participants stressed the importance of partner/ family support. Two partners of participants reported that their own antihypertensive medication was reduced. Participants appreciated the objective feedback on 24-hour sodium excretion and BP as helpful to reduce sodium intake and would have liked even more frequent feedback in the form of objectively measured parameters, such as urinary sodium excretion. Overall, participants valued participation in SUBLIME, rating it 7.8 of 10 , and would recommend use of the program to others.

\section{Process Evaluation and Fidelity}

The web-based self-management program was used by 44 unique users. Although participants were instructed to use the program throughout the intervention, focus groups revealed that it was used primarily in the first months. During the first months, the program was used intensively-daily or every few days. Only a few participants reported using the program longer than 6 months, which is supported by the data logs. Most participants recorded their dietary intake in the evenings. Records were spread over the categories of meals; breakfast (19\%), lunch $(19 \%)$, and dinner $(18 \%)$, and to a lesser extent snacks in the morning (14\%), afternoon (14\%), and evening (16\%). Participants appreciated the feedback on 24-hour sodium excretion and BP as helpful to reduce sodium intake and would have liked even more frequent feedback by objective data. Furthermore, participants mentioned the importance of personal contact with the coach before the e-coaching. Finally, support of partner and family was mentioned as an important factor in reducing sodium intake.

In terms of the providers, 8 of 11 filled out the Measurement Instrument for Determinants of Innovations questionnaire. The providers indicated that the web-based self-management program gave them better insight into the situation of the participants, particularly their motivation, activities, and nutrition intake. A disadvantage was the time needed to familiarize oneself with the program and use it. The providers believed that they were capable of doing the activities needed to carry out the SUBLIME intervention.

\section{Discussion}

In this small and short-term trial, we demonstrated that the SUBLIME intervention reduced sodium intake after the 3month intervention phase. After the maintenance phase, sodium intake decreased in both groups, suggesting that the apparent efficacy during the maintenance phase may have been diminished by inadvertent adoption of the intervention by the control group. BP decreased from baseline, without between-groups differences at 3 months and 9 months postbaseline.

The effect we observed on sodium intake is comparable to interventions in other populations. The PREMIER study in untreated (pre)hypertensive patients consisted of biweekly behavioral counseling in the first half year aiming at weight reduction alone or combined with adherence to the DASH diet, or advice only. ${ }^{26}$ Sodium excretion was decreased by $31.6,32.6$, and $20.6 \mathrm{mmol} / \mathrm{d}$ in the 3 groups, respectively, which is comparable to the 41 $\mathrm{mmol} / \mathrm{d}$ change achieved in our intervention phase and 
also in line with the $44-$ and $33-\mathrm{mmol} / \mathrm{d}$ reductions achieved in the TOHP trials. ${ }^{8}$ Few studies have investigated behavioral interventions in CKD for sodium restriction. The MASTERPLAN study, performed in a setting similar to SUBLIME, was a nurse-led intervention with 11 treatment targets, including adherence to sodium intake $<2,000 \mathrm{mg}$ ( $<90 \mathrm{mmol})$ per day. ${ }^{27}$ MASTERPLAN did not address all components of the self-regulation theory and had a long intervention phase of 2 years, averaging 7.2 outpatient clinic visits yearly. ${ }^{27,28}$ MASTERPLAN had no effect on sodium excretion (150 vs $148 \mathrm{mmol} / \mathrm{d}$ ). ${ }^{28}$ A multidisciplinary behavioral approach was shown effective in the ESMO intervention in CKD, which also successfully reduced sodium excretion and $\mathrm{BP}$ in the short term. ${ }^{9}$

Higher sodium intake was shown to correlate with higher antihypertensive drug use in 141 patients with CKD stages 4 and $5 .^{29}$ In SUBLIME, although some changes in antihypertensive medication dosage occurred, no significant within-group difference in incidence of dose reduction was observed.

The study has several strengths. The intervention was based on a sound theoretical framework and was designed in a multidisciplinary setting, with input from psychologists, nephrologists, dietitians, and representatives from the Dutch Kidney Patients Association and in co-creation with patients. Our study population consisted of several CKD stages and also included kidney transplant recipients because these patients also commonly have hypertension and high sodium intake. ${ }^{30}$ Further, the intervention was evaluated using data logs and focus groups to identify barriers and facilitators for implementation in clinical practice.

Limitations of the study include lack of dietary data, postrandomization loss to follow-up, short-term followup, and small sample size. Statistical power was limited by sample size and because the power calculation was based on the treatment effect observed in the ESMO Study, that is, a reduction of $30.3 \mathrm{mmol} / \mathrm{d}$. We anticipated a larger effect for the present study, but this was apparently overly optimistic, particularly for the maintenance phase. Furthermore, the preponderance of male participants in our study may affect generalizability. Finally, sodium intake may have been subject to the so-called Hawthorne effect. ${ }^{31}$ Participants' awareness of being in a sodium intervention study might have affected the outcome even without exposure to the intervention. For instance, control participants might have become more vigilant about sodium intake simply by being enrolled in the SUBLIME study. Frequent 24-hour urinary sodium measurements during the study may have motivated control participants to achieve the gradual significant reduction in sodium intake that was observed even without the active coaching. The different time course of sodium reduction between the groups may be of interest. In the intervention group, the largest sodium reduction occurred during the intervention phase, that is, when participants most actively used the web-based self-management program, as evidenced by the data logs. In the focus groups, participants reported that their acquired insights into their diet affected their use of the web-based self-management program. As well, they indicated that after achievement of their target sodium intake, they stopped using the program regularly, which occurred when sodium reduction became similar to that in the control group. A logical interpretation would be that a combination of selection effect (motivation for sodium reduction), awareness of being studied, and feedback from urinary sodium results exerted a gradual effect on sodium intake that was accelerated and intensified by the coaching program.

The feedback by our participants obtained in the focus groups provides important lessons from our study for future interventions. First, participants considered feedback from objective data, such as 24-hour urine sodium excretion, highly useful. Second, they desired face-to-face contact with their personal coach before e-coaching sessions, thus favoring blended care over a pure e-health approach. Moreover, they considered social support from partner and family essential. Also, the intervention should be tailored to personal sodium-reduction barriers and personal preferences, such as whether to participate in group sessions. Finally, the web-based self-management program should be user-friendly. Future studies should elucidate whether effectively accounting for these factors can further enhance the efficacy of sodium management in patients with CKD on a long-term basis and whether these principles can also be applied for management of other dietary factors.

In conclusion, the SUBLIME study presents a potentially effective strategy for dietary sodium restriction in CKD in clinical practice, although future larger and longer term studies are needed to test long-term efficacy.

\section{Article Information}

SUBLIME Investigators: P.J.M. van der Boog, S. van Dijk, G.J. Navis (project leaders); J.K. Humalda (project coordination); G. Klaassen, Y. Meuleman, L.C. Verschuur, E.J.M. Straathof, O.A. Blanson Henkemans, W.J.W. Bos, M.H. de Borst, G.D. Laverman, W. Otten, K.M. Vermeulen, and H. de Vries (investigators).

Authors' Full Names and Academic Degrees: Jelmer K. Humalda, MD, PhD, Gerald Klaassen, MSc, Hanne de Vries, MD, Yvette Meuleman, PhD, Lara C. Verschuur, MD, Elisabeth J.M. Straathof, MD, Gozewijn D. Laverman, MD, PhD, Willem Jan W. Bos, MD, $\mathrm{PhD}$, Paul J.M. van der Boog, MD, PhD, Karin M. Vermeulen, PhD, Olivier A. Blanson Henkemans, PhD, Wilma Otten, PhD, Martin H. de Borst, MD, PhD, Sandra van Dijk, PhD, and Gerjan J. Navis, MD, PhD.

Authors' Affiliations: Division of Nephrology, Department of Internal Medicine, University Medical Center Groningen, University of Groningen, Groningen (JKH, GK, LCV, EJMS, MHdB, GJN); Department of Nephrology, ZGT Hospital, Almelo/Hengelo (HdV, GDL); Department of Health, Medical and Neuropsychology, Faculty of Social and Behavioral Sciences, Leiden University (YM, SvD); Department of Clinical Epidemiology, Leiden University Medical Center, Leiden (YM); Department of Internal Medicine, St. Antonius Hospital, Nieuwegein (WJWB); Department of Internal Medicine, Leiden University Medical Center, Leiden (WJWB, PJMvdB); Department of Epidemiology, University Medical Center 
Groningen, University of Groningen, Groningen (KMV); and Department of Child Health, Netherlands Organization for Applied Scientific Research (TNO), Leiden, the Netherlands (OABH, WO).

Address for Correspondence: Gerald Klaassen, MSc, Department of Internal Medicine, Division of Nephrology, University Medical Center Groningen (AA53), PO Box 30.001, 9700 RB Groningen, the Netherlands. E-mail: g.klaassen@umcg.nl

Authors' Contributions: Research idea and study design: JKH, GK, YM, GDL, WJWB, PJMB, SvD, GJN; intellectual contributions/data interpretation: JKH, GK, HdV, YM, LCV, EJMS, GDL, WJWB, PJMB, MHdB, SvD, GJN; statistical analysis: JKH, GK, YM; cost analysis: $\mathrm{KMV}$; independent focus groups: $\mathrm{OABH}$, WO. Each author contributed important intellectual content during manuscript drafting or revision and accepts accountability for the overall work by ensuring that questions pertaining to the accuracy or integrity of any portion of the work are appropriately investigated and resolved.

Support: The SUBLIME study was funded by a grant from the Netherlands Organization for Health Research and Development (ZonMw; project number 837001005 of the "Doelmatigheidsonderzoek 2013-2015" program) and by the Dutch Kidney Foundation (project code PV48). The funding body was involved in the study design and data collection (ie, assessment of costs of the intervention vs routine care, and our collection of these data was mandated by the funding body). The funders were not involved in the analyses, reporting, or decision to submit for publication. The e-health module was developed by Bonstato, in collaboration with S. van Dijk and Y. Meuleman.

Financial Disclosure: The authors declare that they have no relevant financial interests.

Acknowledgements: We acknowledge the contribution of E. Buskens, C. van Daelen, M.W. Dijk-Schaap, B. Gabel, J.D. de Groot, E. van Houdt, C.G.J. Indemans, T. Kok, I.N. Kunnekes, H. Piels, T. Rövekamp, I. Schultze, A. Spijker, M. Storm, I.M. van Weverwijk, D. Wiefferink, and Nefrovisie.

Data Sharing: The trial protocol and deidentified participant data are available upon reasonable request until 2 years after publication, via the corresponding author. The data can be made available to researchers who provide a methodologically sound proposal in their request. Reuse of the data can be permitted upon reasonable request via the corresponding author.

Peer Review: Received February 26, 2019. Evaluated by 2 external peer reviewers, with direct editorial input from a Statistics/Methods Editor, an Associate Editor, and the Editor-in-Chief. Accepted in revised form October 21, 2019.

\section{References}

1. Humalda JK, Navis G. Dietary sodium restriction: a neglected therapeutic opportunity in chronic kidney disease. Curr Opin Nephrol Hypertens. 2014;23(6):533-540.

2. Kidney Disease Outcomes Quality Initiative (K/DOQI). K/DOQI clinical practice guidelines on hypertension and antihypertensive agents in chronic kidney disease. Am J Kidney Dis. 2004;43(5)(suppl 1):S1-S290.

3. Rensma P, Hagen E, van Bommel E, et al. Werkgroep Richtlijn Chronische Nierschade. Richtlijn Voor de Behandeling van Atiënten Met Chronische Nierschade (CNS). Huisarts en Wetenschap. 2009;52:586-595.

4. National Kidney Foundation. KDIGO clinical practice guideline for the management of blood pressure in chronic kidney disease. Kidney Int Suppl. 2012;2(5):337-414.

5. Lambers Heerspink $\mathrm{HJ}$, Holtkamp FA, Parving $\mathrm{H}-\mathrm{H}$, et al. Moderation of dietary sodium potentiates the renal and cardiovascular protective effects of angiotensin receptor blockers. Kidney Int. 2012;82(3):330-337.

6. Vegter S, Perna A, Postma MJ, Navis G, Remuzzi G, Ruggenenti P. Sodium intake, ACE inhibition, and progression to ESRD. J Am Soc Nephrol. 2012;23(1):165-173.

7. de Borst M, Navis G. Sodium intake, RAAS-blockade and progressive renal disease. Pharmacol Res. 2016;107:334-351.

8. Cook N, Cutler J, Obarzanek E, et al. Long term effects of dietary sodium reduction on cardiovascular disease outcomes: observational follow-up of the Trials of Hypertension Prevention (TOHP). BMJ. 2007;334(7599):885-888.

9. Meuleman Y, Hoekstra T, Dekker FW, et al. Sodium restriction in patients with CKD: a randomized controlled trial of selfmanagement support. Am J Kidney Dis. 2017;69(5):576-586.

10. Maes S, Karoly P. Self-regulation assessment and intervention in physical health and illness: a review. App/ Physiol. 2005;54: 267-299.

11. Plaete J, De Bourderauduij I, Verloigne M, Crombez G. Acceptability, feasibility and effectiveness of an eHealth behaviour intervention using self-regulation: "MyPlan." Patient Educ Couns. 2015;98(12):1617-1624.

12. van Dyck D, Plaete J, Cardon G, Crombez G, De Bourdeaudhuij I. Effectiveness of the self-regulation eHealth intervention "MyPlan1.0." on physical activity levels of recently retired Belgian adults: a randomized controlled trial. Health Educ Res. 2016;31(5):653-664.

13. van der Mispel C, Poppe L, Crombez G, Verloigne M, De Bourdeaudhuij I. A self-regulation-based eHealth intervention to promote a healthy lifestyle: investigating user and website characteristics related to attrition. J Med Internet Res. 2017;19(7):e241.

14. Meuleman $Y$, ten Brinke L, Kwakernaak AJ, et al. Perceived barriers and support strategies for reducing sodium intake in patients with chronic kidney disease: a qualitative study. Int J Behav Med. 2015;22(4):530-539.

15. Meuleman Y, Hoekstra T, Dekker F, van der Boog P, van Dijk S; ESMO study group. Perceived sodium reduction barriers among patients with chronic kidney disease: which barriers are important and which patients experience barriers? Int J Behav Med. 2018;25(1):93-102.

16. Valente M, Hillege H, Navis G, et al. The Chronic Kidney Disease Epidemiology Collaboration equation outperforms the Modification of Diet in Renal Disease equation for estimating glomerular filtration rate in chronic systolic heart failure. Eur $J$ Heart Fail. 2014;16(1):86-94.

17. Mancia G, Fagard R, Narkiewicz K, et al. 2013 ESH/ESC practice guidelines for the management of arterial hypertension. Blood Press. 2014;23(1):3-16.

18. Ware J, Kosinski M, Turner-Bowker D, Gandek B. How to Score Version 2 of the SF-12 Health Survey (with a Supplement Documenting Version 1). Lincoln, RI: QualityMetric Inc; 2002.

19. EuroQol Group. EuroQol - A new facility for the measurement of health-related quality of life. Health Policy. 1990;16:199-208.

20. Petkov J, Harvey P, Battersby M. The internal consistency and construct validity of the partners in health scale: validation of a patient rated chronic condition self-management measure. Qual Life Res. 2010;19:1079-1085.

21. Hakkaart-van Rooijen L, Tan SS, Bouwmans CAM. Handleiding voor Kostenonderzoek: Methoden en Standaard Kostprijzen voor Economische Evaluaties in de Gezondheidszorg. 3rd ed. Diemen, the Netherlands: College voor zorgverzekeringen; 2010.

22. Fleuren M, Paulussen $T$, van Dommelen $P$, van Buuren $S$. Measurement Instrument for Determinants of Innovations (MIDI). Leiden, the Netherlands: TNO; 2014. 
23. Slagman M, Waanders F, Hemmelder M, et al. Moderate dietary sodium restriction added to angiotensin converting enzyme inhibition compared with dual blockade in lowering proteinuria and blood pressure: randomised controlled trial. BMJ. 2011;343:d4366.

24. Vogt L, Waanders F, Boomsma F, de Zeeuw D, Navis G. Effects of dietary sodium and hydrochlorothiazide on the antiproteinuric efficacy of losartan. J Am Soc Nephrol. 2008;19(5): 999-1007.

25. Kwakernaak AJ, Krikken JA, Binnenmars SH, et al. Effects of sodium restriction and hydrochlorothiazide on RAAS blockade efficacy in diabetic nephropathy: a randomised clinical trial. Lancet Diabetes Endocrinol. 2014;2(5):385-395.

26. Chang A, Batch C, McGuire H, et al. Association of a reduction in central obesity and phosphorus intake with changes in urinary albumin excretion: the PREMIER study. Am J Kidney Dis. 2013;62(5):900-907.
27. van Zuilen $A$, Bots $M$, Dulger $A$, et al. Multifactorial intervention with nurse practitioners does not change cardiovascular outcomes in patients with chronic kidney disease. Kidney Int. 2012;82:710-717.

28. van Zuilen A, Wetzels J, Bots M, van Blankestijn P; MASTERPLAN study group. MASTERPLAN: study of the role of nurse practitioners in a multifactorial intervention to reduce cardiovascular risk in chronic kidney disease patients. J Nephrol. 2008;21 (3):261-267.

29. Lerchl K, Rakova N, Dahlmann A, et al. Agreement between 24hour salt ingestion and sodium excretion in a controlled environment. Hypertension. 2015;66(4):850-857.

30. van den Berg E, Geleijnse J, Brink E, et al. Sodium intake and blood pressure in renal transplant recipients. NDT. 2012;27(8): 3352-3359.

31. Mccambridge J, Witton J, Elbourne DR. Systematic review of the Hawthorne effect: new concepts are needed to study research participation effects. J Clin Epidemiol. 2014;67(3):267-277. 